\title{
Rheological Characteristics of Loam Compositions with Mineral Additives of Different Genesis and Morfology
}

\section{S. A. Shakhov and N. Yu. Nikolaev}

Siberian Transport University, Russia, 630049, Novosibirsk, Dusy Kovalchuk 191

\section{Abstract}

Structural clay products manufacturing is depends on the potential of local raw materials. Shoddy silty loams are the main component of molding mixtures in view of shortage of the quality clays. Therefore, methods for determining the structural characteristics of molding compounds are becoming important.

The objective of study is the influence of mineral additives different genesis and morphology at structural characteristics and molding properties of the compounds

Corresponding Author:

N. Yu. Nikolaev

nikolaevh13@mail.ru

Received: 10 February 2018

Accepted: 14 April 2018

Published: 7 May 2018

Publishing services provided by Knowledge

(c) S. A. Shakhov and N. Yu. Nikolaev. This article is distributed under the terms of the Creative Commons

Attribution License, which permits unrestricted use and redistribution provided that the original author and source are credited.

Selection and Peer-review under the responsibility of the RFYS Conference Committee. based on shoddy silty loams.

Photometrical sedimentometer FSH-6K and optical microscopy method were used for the determining of granulometric compositions and morphological properties of the additives. Conical rheometer method was used for the determining plastic strength of the moulding compounds. Shear plastometer method was used to determining values of the low elastic, high elastic and plastic deformations.

It had defined the optimal values of molding clay compound's moisture in which molding compositions had being tested. Optimal values of the molding composition's moisture in which molding compounds has not subjected to negative influences of the gravitational water are equal to $15-19 \%$. Structural constants were calculated for molding compositions based on different kinds of additives. Values of the percent of low elastic, high elastic and plastic deformation were calculated on the grounds of rheological curves. Optimal values of composition's structural characteristics were accepted from the condition of three types of deformations.

\section{The relevance of research}

Ceramic masses are exposed to various kinds of mechanical influences in the process of molding. Deformation behavior of such compositions is depending by the properties

S OPEN ACCESS of coagulation structure. 
The development of coagulation structure is determined by the ability of the molding compounds to plastic and elastic deformations [1]. In this case, sufficiently complete information of deformation behavior can be obtained from rheological curves $[2,3]$.

Basic structural and mechanical characteristics can be used as a criterion for evaluating to molding properties of clay raw materials, as well as for determining the statistical correlation between these characteristics and the natural properties of loams $[4,5]$. Theoretical positions of physicochemical mechanics allows the possibility of effective control rheology of disperse systems not only due to mechanical activation and the use of surface-active substance, but also to the selection of corrective mineral additives of various genesis. It was installed a large number of additives, which have a certain effect to the deformation behavior of loamy molding compositions $[6,7]$.

The task of selecting the rational composition of the charge, which provides the rheological properties required for plastic molding, is even more complicated with considering the tendency to expand use of multicomponent additives to improve the properties of ceramics [8-11]. It should be noted that the influence of mineral particles of different morphology to the rheological behavior of the molding clay compositions is poorly understood.

In this work group of mineral additives, with the help of which, according to our estimates, it is possible to control the structural and mechanical properties and rheological behavior of the molding masses from low-grade clay raw materials, was studied.

\section{Materials and methods}

Clayey loams from Kamyshenskoye deposit of Novosibirsk region were used as a clay raw material. These soils are coarsely dispersed (clay content less than $20 \mathrm{wt}$. \%). Plastic properties of clayey loam refers to the moderately plastic class.

Wollastonite, diopside and granulated blast-furnace slag were used as modifying additives.

Elongated needle particles are a feature of natural wollastonite. According to some studies [12], structure of wollastonite's particles determines the possibility of its use as reinforcing agent for the production of ceramic materials with increased strength.

According to the results of analysis structure and phase composition, particles of blast-furnace slag are permeated by micro- and macropores. The content of the vitreous in these particles is $65-97 \%$. The crystallized phases was mainly represented 
by the pseudowollastonite $\mathrm{CaO} \cdot \mathrm{SiO}_{2}(\mathrm{~d} / \mathrm{n}, \mathrm{A}-4.162,2.921)$ and microlites of melilite $\mathrm{Ca}_{2}$ (Al, Mg) $\left[(\mathrm{Si}, \mathrm{Al})_{2} \mathrm{O}_{7}\right]$ (d / $\left.\mathrm{n}, \mathrm{A}-3.105,2.876,2.738 .2 .522\right)$. Powders of slag were mechanically activated to $S=4000 \mathrm{~cm}^{2} / g$.

Diopside is a mineral from the group of pyroxenes, cristallizing in the monoclinic syngony. Diopside-bearing rocks are used in the production of building ceramic materials as a modifying additive, which reduces the shrinkage processes. Complex of alkalineearth oxides, containing in a diopside rock, can also have a significant effect on the molding properties of ceramic masses. Powders of diopside were mechanically activated to $S=4000 \mathrm{~cm}^{2} / \mathrm{g}$.

Grading and morphological features of modifying additives were analyzed by photometric sedimentometer FSH-6K, as well as by optical microscopy.

The influence of additives to the coagulation structure's characteristics was evaluated, using methods of physicochemical mechanics. Plastic strength of yielding systems was carried out by conical plastometer. Values of fast elastic, slow elastic and plastic deformation were determined by shear plastometer.

Results of measurements by shear plastometer make it possible to obtain rheological curves $[6,7,13,14]$. On the grounds of these curves, constants of deformation properties of molding clay compounds with undamaged structure has been determined graphically. According to the series of curves, for each sample structural and mechanical characteristics, such as relaxation period, plasticity and elasticity, were calculated.

\section{Results of the study}

The molding properties of compounds, based on clay raw materials, can be characterized by the value of the rheological constants, which determined by the limiting shear stress at a low strain rates. Modulus of fast elastic deformation and modulus of slow elastic deformation evaluated at optimal molding moisture. In particular, change of the specific surface area of slag additive can have a significant effect to the suspension's deformation properties. Worsening of the molding properties, consisting to the growth of deformation modulus (fast elastic and slow elastic), is observed with $S=2000 \mathrm{~cm}^{2} / \mathrm{g}$ (Figure 3). Thus, studies of the influence by slag's additive with a specific surface area above $2000 \mathrm{~cm}^{2} / g$ to the rheological characteristics of loamy suspensions are becomes interesting.

Also, changes in deformation behavior of charges with increasing moisture is associated with an increase in the distance between the particles of the solid phase, due 


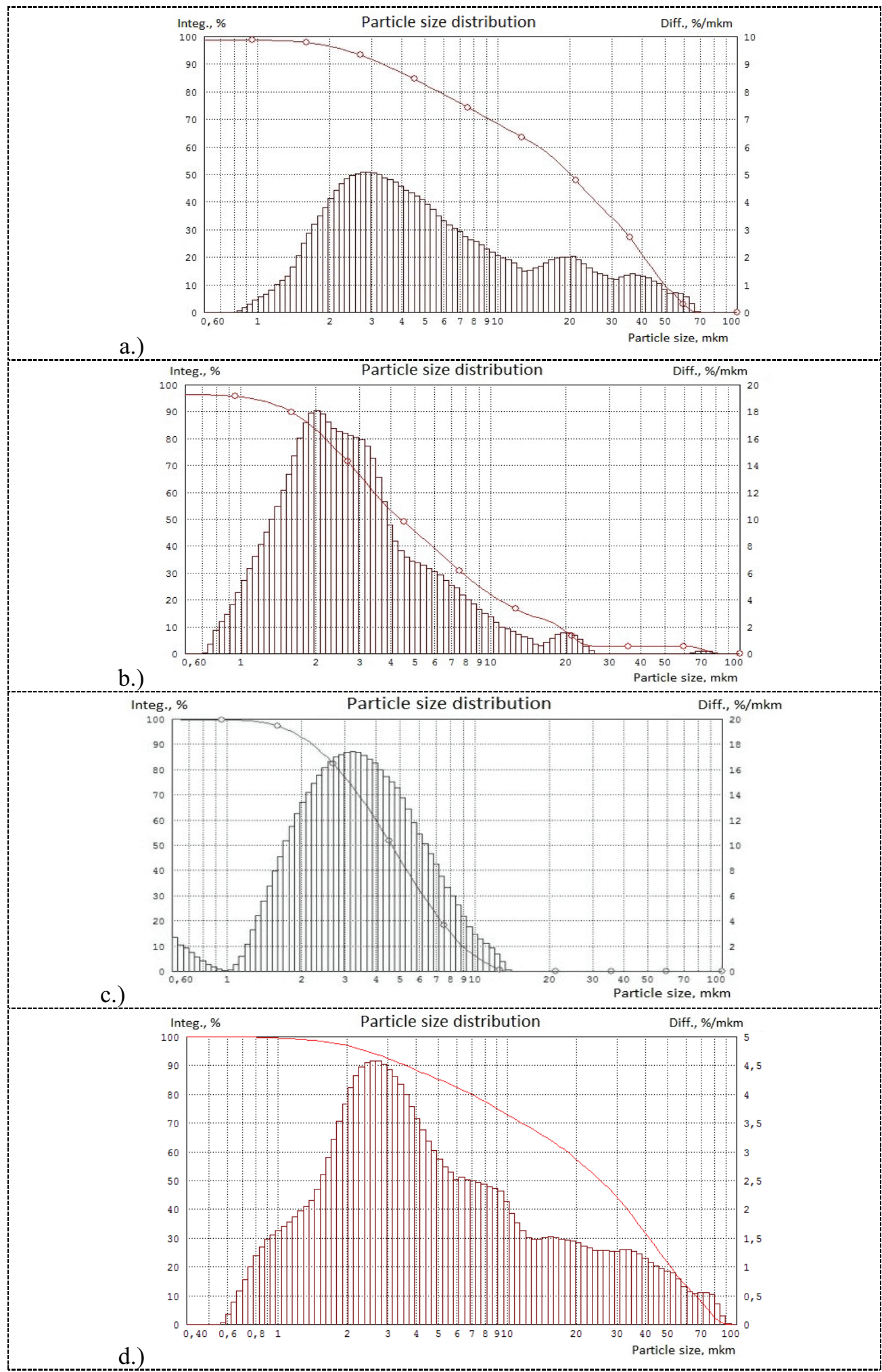

Figure 1: Granulometric composition of materials: a - loam; b - blast-furnace slag; c - wollastonite; $d$ diopside.

to the development of hydrate shells on them and the appearance of gravitational water in the system $[11,15,16]$. Thus, suspensions samples were tested at optimum 
a.)
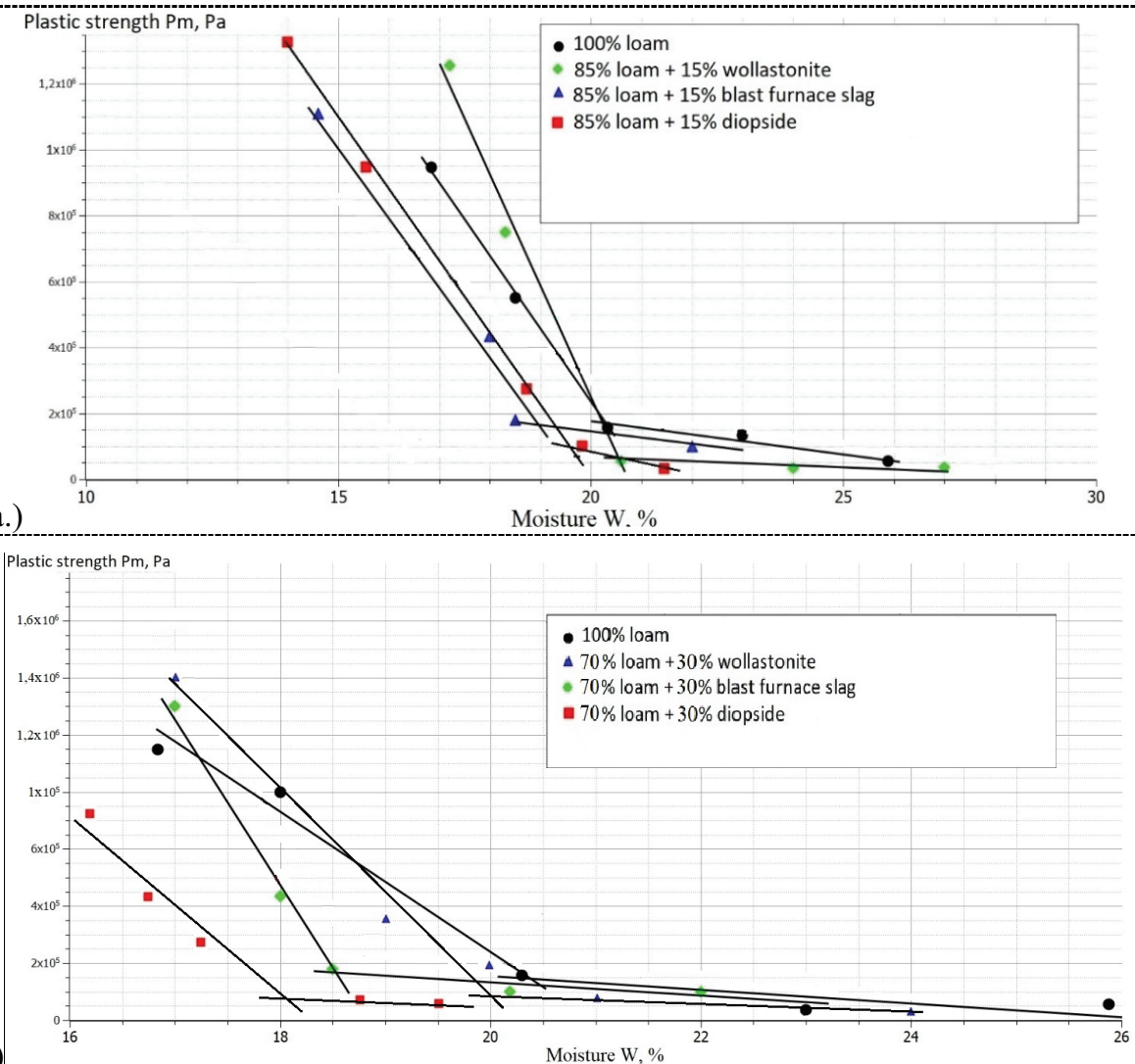

Figure 2: Results of composition's conical plastometry: a - 15\% additive's content; b - 30\% additive's content.

moisture values, characterized the areas of consistent development of hydrate shells and appearance of significant amounts of gravitational water [17-20]. Normal molding moisture is determined by the point of intersection two straight segments of dependence plastic strength from humidity (Figure 2).

The ratio of various deformation types is the criterion for the suitability of clay suspensions to plastic molding. It should be noted, that there is no unified opinion on the issue of the optimal correlation of deformations. In work [8] preference is given to the molding masses of the first and especially the second structural types. The authors of some studies $[5,6]$ recommend to use molding masses with uniform development of all types of deformations. At the same time, any structural types are not identified as optimal. It is the latter view that is most preferable, if we take into account the structural characteristics of the compositions used on extrusion molding technology.

The rheological properties of molding compositions with additives for evaluation their structural, mechanical and deformation characteristics were calculated. As can be seen (Figure 4), clayey loam refers to the IV structural-mechanical type. Loam is characterized by an uneven distribution of 3 deformation. A feature of this type is the 


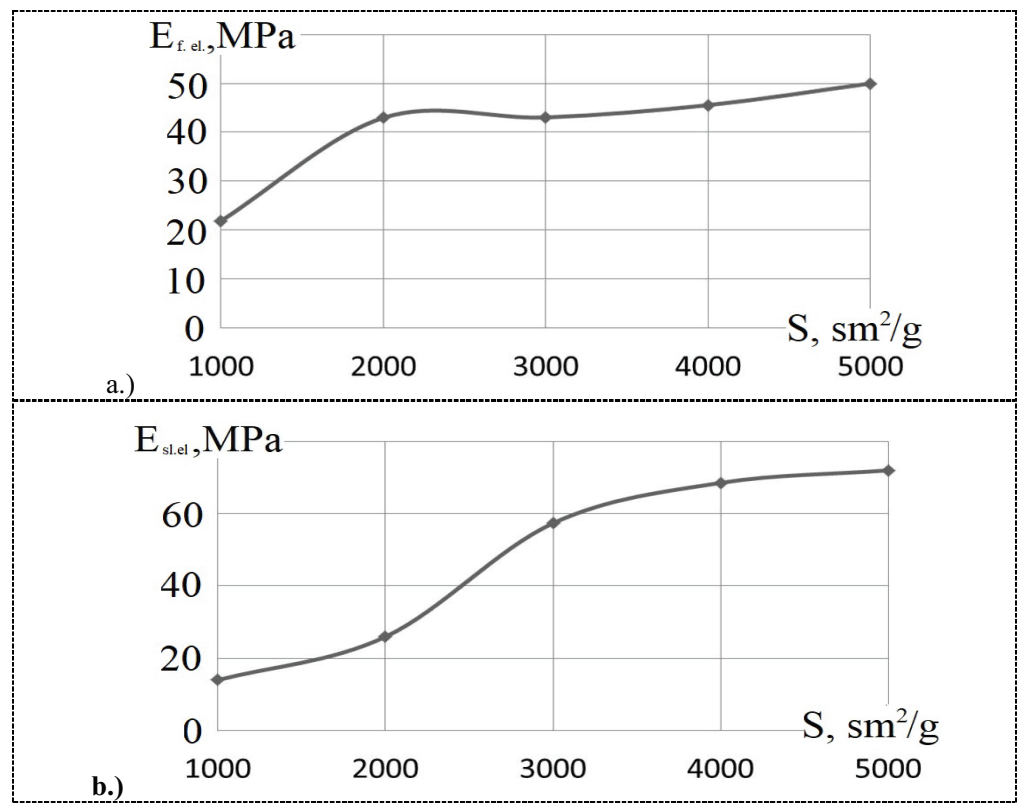

Figure 3: Influence of the specific surface area of the slag additive (15 wt. \%). to the rheological constants of loam: a - modulus of fast elastic deformation; $b$ - modulus of slow elastic deformation.

preferential development of plastic deformations, low values of fast and slow elastic deformations and period of relaxation. Compounds of this type are very plastic and easily deformed. These molding masses are susceptible to plastic destruction [7, 8, 21, 22].

Addition of slag, in contradistinction to a similar amount of diopside, increases the viscosity of suspensions, which is due to its lyophobic properties, increasing number of contacts without of a layer of the dispersion medium [7].

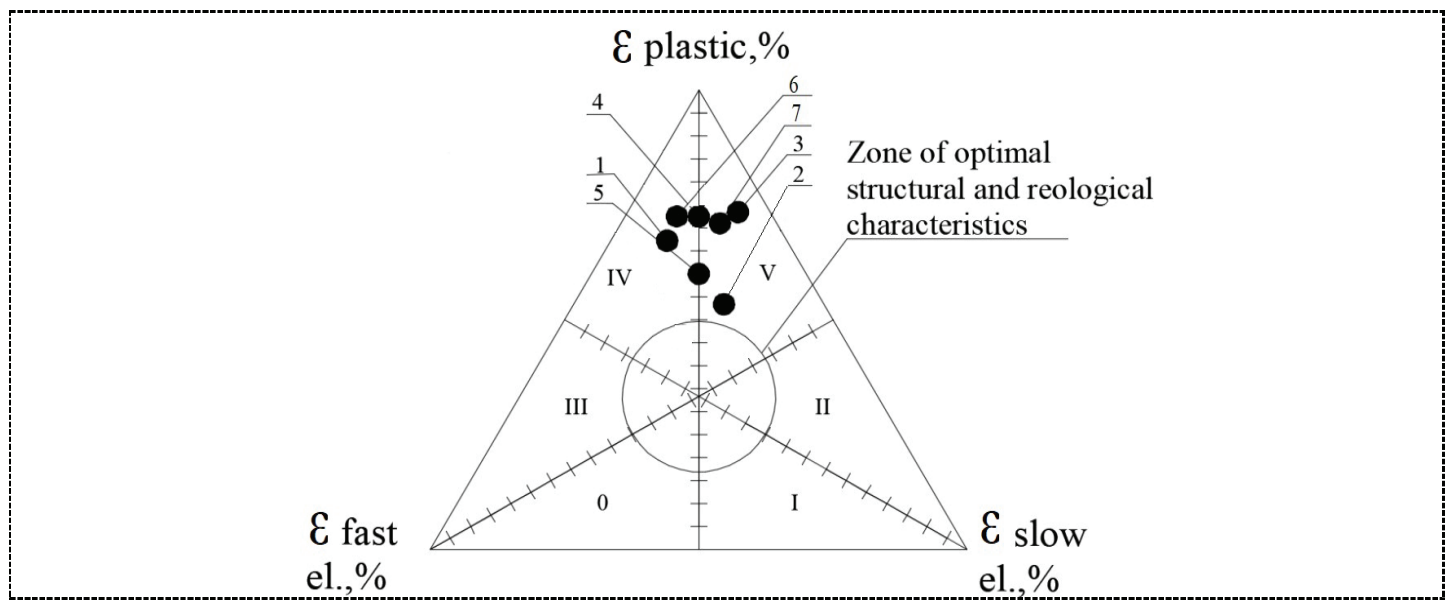

Figure 4: Triple diagram of reduced deformations for the charge of composition:

The addition of wollastonite strengthens the coagulation structure. It is expressed to the growth of the relaxation period and viscosity of suspensions. At the same time, blast furnace slag, as well as wollastonite, contribute to the growth of slow elastic 

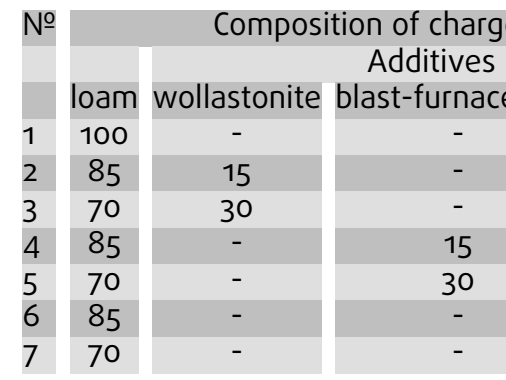

blast-furnace slag diopside

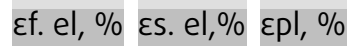

\begin{tabular}{|l|c|c|}
\hline 28 & 7 & 65 \\
\hline 29 & 19 & 52 \\
\hline 17 & 10 & 73 \\
\hline 14 & 14 & 72 \\
\hline 20 & 20 & 60 \\
\hline 11 & 18 & 71 \\
\hline 17 & 13 & 70 \\
\hline
\end{tabular}

T rel, sec

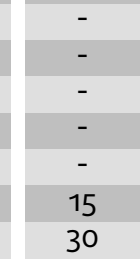

17

13

70

322

538

231

192

333

158

244

deformations (Figure 3). The addition of slag reduces viscosity. For these suspensions increase of elasticity is more significant than in composition with wollastonite.

An increase of content to slag and diopside additives to $30 \%$ in the composition of the molding compound, slightly reduces the percentage of plastic deformations. It is a decrease of the optimum molding moisture content of the charges with the addition of slag. An increase of the plastic properties of compositions with $30 \%$ diopside content can be associated with a coagulating action cations of alkaline earth metals towards to clay particles (Table 1 ).

TABLE 1: Rheological characteristics of compositions.

\begin{tabular}{|c|c|c|c|c|c|}
\hline Composition & $\mathrm{W}_{\text {opt }}, \%$ & $\mathrm{P}_{m, o p t,} \mathrm{~Pa}$ & Elasticity & $\begin{array}{l}\text { Plasticity, } \\
\cdot 10^{-6} \mathrm{sec}^{-1}\end{array}$ & $\begin{array}{l}\text { Viscosity, } \\
\text { Pa.sec }\end{array}$ \\
\hline Loam 100\% & 20,0 & 200000 & 0,191 & 2,192 & 1824 \\
\hline Loam $85 \%+15 \%$ slag & 18,5 & 150000 & 0,486 & 0,964 & 8817 \\
\hline Loam $70 \%+30 \%$ slag & 17,5 & 250000 & 0,487 & 1,658 & 2110 \\
\hline Loam $85 \%+15 \%$ diopside & 19,5 & 110000 & 0,606 & 2,209 & 1810 \\
\hline Loam $70 \%+30 \%$ diopside & 18,0 & 80000 & 0,418 & 10,300 & 339 \\
\hline Loam $85 \%+$ wollastonite $15 \%$ & 20,5 & 70000 & 0,392 & 0,702 & 5693 \\
\hline Loam $70 \%+$ wollastonite $30 \%$ & 18,0 & 180000 & 0,354 & 1,975 & 3036 \\
\hline
\end{tabular}

\section{Conclusions}

Experimental researches of rheological behavior clay loam compositions, modifying additives of different genesis and morphology, have shown that the introduction of mineral additives into the charge allows changing the relaxation period, elasticity, plasticity and viscosity of suspensions. 
It can be concluded, that the introduction of additives with different particle morphology makes it possible to change the relationship between different types of deformations. However, none of the additives provides a uniform development of all deformation kinds in the molding mass.

In this way, it seems reasonable the effectiveness of controlling the rheological behavior of molding masses with the help of different functional purpose composite additives.

\section{References}

[1] Urev, N. B., 1988. Fiziko-himicheskie osnovy tehnologii dispersnyh sistem i materialov [Physicochemical basis of dispersed systems and materials]. M.: Himiya, Pp: 256. (in Russian)

[2] Danforth, S. C., I. K.Talo and S. Kwark, 1989. Rheological Behavior of Injection Molding Ceramic-ceramic Composite Formulations. CIM Bull, 926: 88.

[3] Pivinskij, Yu. E., 1995. Reologiya v tehnologii keramiki i ogneuporov. Dispersnye sistemy, metody issledovaniya i ocenki ih reologicheskih svojstv [Rheology in the technology of ceramics and refractories. Disperse systems, methods for studying and evaluating their rheological properties]. Ogneupory, 12: 11-19. (in Russian)

[4] Ozkan, N., C. Oysu, B. J. Briscoe and I. Aydin, 1999. Rheological analysis of ceramic pastes. European Ceramic Society, 19: 2883-2891.

[5] Doraiswamy, D., I. K. Tsao and S. C. Danforth, 1989. Analysis of the Rheological Behavior of Concetrated Ceramic Suspentions. Ceram. Mater. and Compon. Engines: 380-398.

[6] Ilin, A. P., V. Yu. Prokofev, 2002. Upravlenie strukturno-mehanicheskimi svojstvami formovochnyh mass pri poluchenii ekstrudirovannyh nositelej i katalizatorov [Management of structural and mechanical properties of the molding compounds in the preparation of extruded supports and catalysts]. Kataliz v promyshlennosti, 6: 45-51. (in Russian)

[7] Ilin, A. P. and V. Yu. Prokofev, 2004. Fiziko-himicheskaya mehanika v tehnologii katalizatorov i sorbentov: Monografiya [Physico-chemical mechanics of catalysts and adsorbents technologies: Monograph]. Ivan. gos. him.-tehnol. un-t. Ivanovo, PP: 316. (in Russian)

[8] Kruglickij, N. N., 1968. Fiziko-himicheskie osnovy regulirovaniya svojstv dispersij glinistyh materialov [Physical and chemical base of regulation properties of clay 
materials dispersions]. Kiev: Naukova dumka, pp: 244. (in Russian)

[9] Chimmili, S., D. Doraiswamy and R. K. Gupta, 1998. Shear-induced agglomeration of particulate suspensions. Ind. Eng. Chem. Res., 37 (6): 2073-2077.

[10] Doraiswamy, D., A. N. Mujumdar, I. Tsao, A. N. Beris, S. C. Danforth, A. B. Metzner, 1991. The Cox-Merz rule extended: A rheological model for concentrated suspensions and other materials with yield stress. Journal of Rheology, 35: 647-685.

[11] Balkevich, V. L., Yu. M. Mosin and M. N. Firsova, 1980. Opredelenie plasticheskoj prochnosti dlya ocenki formovochnyh svojstv keramicheskih mass [Determination of plastic strength for evaluation of molding properties of ceramic masses]. Steklo i keramika, 4: 16-17. (in Russian)

[12] Ciullo, R. and S. Robinson, 2009. Wollastonite - versatile functional filler. Paint and Coatings Industry, 11, pp: 50.

[13] Briscoe, B. J. and N. Ozkan, 1997. Characterization of ceramic pastes by an indentation hardness test. J. European Ceramic Society, 17, 14: 1675-1683.

[14] Armstrong, M.J., A.N. Beris, S.A. Rogers and N.J. Wagner, 2016. Dynamic shear rheology of a thixotropic suspension: Comparison of an improved structure-based model with large amplitude oscillatory shear experiments. Journal of Rheology, 60(3): 433-450.

[15] de Souza Mendes, P. R., R. L. Thompson, A. A. Alicke, and R. T.Leite, 2014. The quasilinear large-amplitude viscoelastic regime and its significance in the rheological characterization of soft matter. J. Rheol., 58: 537-561.

[16] O'Brien, V. T. and M. E. Mackay, 2000. Stress components and shear thickening of concentrated hard sphere suspensions. Langmuir, 16 (21): 7931-7938.

[17] Jacob, A. R., A. P. Deshpande and L. Bouteiller, 2014. Large amplitude oscillatory shear of supramolecular materials. J. Non-Newtonian Fluid Mech, 206: 40-56.

[18] Coussot, P., A. I. Leonov, and J. M. Piau, 1993. Rheology of concentrated dispersed systems in a low molecular weight matrix. J. Non-Newtonian Fluid Mech, 46: 179217.

[19] Kim, J. M., A. P. R. Eberle, A. K. Gurnon, L. Porcar, and N. J. Wagner, 2014. The microstructure and rheology of a model, thixotropic nanoparticle gel under steady shear and large amplitude oscillatory shear (LAOS). J. Rheol., 58(5): 1301-1328.

[20] Eberle, A. P. R., and L. Porcar, 2012. Flow-SANS and Rheo-SANS applied to soft matter. Curr. Opin. Colloid Interface Sci., 17: 33-43.

[21] Pignon, F., A. Magnin, and J. Piau, 1997. Butterfly light scattering of a sheared thixotropic clay gel. Phys. Rev. Lett., 79(23): 4689-4692. 
[22] De Bruyn, J. R., F. Pignon, E. Tsabet, and A. Magnin, 2007. Micron-scale origin of the shear-induced structure in Laponite-poly (ethylene oxide) dispersions. Rheol. Acta, 47: $63-73$. 